\title{
Spasticity, Motor Recovery, and Neural Plasticity after Stroke
}

\author{
Sheng $L i^{1,2 *}$ \\ 'Department of Physical Medicine and Rehabilitation, University of Texas Health Science Center, Houston, TX, USA, \\ ${ }^{2}$ TIRR Memorial Hermann Research Center, TIRR Memorial Hermann Hospital, Houston, TX, USA
}

Spasticity and weakness (spastic paresis) are the primary motor impairments after stroke and impose significant challenges for treatment and patient care. Spasticity emerges and disappears in the course of complete motor recovery. Spasticity and motor recovery are both related to neural plasticity after stroke. However, the relation between the two remains poorly understood among clinicians and researchers. Recovery of strength and motor function is mainly attributed to cortical plastic reorganization in the early recovery phase, while reticulospinal (RS) hyperexcitability as a result of maladaptive plasticity, is the most plausible mechanism for poststroke spasticity. It is important to differentiate and understand that motor recovery and spasticity have different underlying mechanisms. Facilitation and modulation of neural plasticity through rehabilitative strategies, such as early interventions with repetitive goal-oriented intensive therapy, appropriate non-invasive brain stimulation, and pharmacological agents, are the keys to promote motor recovery. Individualized rehabilitation protocols could be developed to utilize or avoid

\section{OPEN ACCESS}

Edited by:

Ayrton R. Massaro,

Hospital Sirio-Libanes, Brazil

Reviewed by:

Friedhelm C. Hummel, University of Hamburg, Germany

Guang H. Yue,

Kessler Foundation, USA

*Correspondence: Sheng $\mathrm{LI}$ sheng.li@uth.tmc.edu

Specialty section: This article was submitted to Stroke, a section of the journal

Frontiers in Neurology

Received: 05 July 2016 Accepted: 15 March 2017 Published: 03 April 2017

Citation:

Li S (2017) Spasticity, Motor Recovery, and Neural Plasticity after Stroke. Front. Neurol. 8:120. doi: 10.3389/fneur.2017.00120 the maladaptive plasticity, such as RS hyperexcitability, in the course of motor recovery. Aggressive and appropriate spasticity management with botulinum toxin therapy is an example of how to create a transient plastic state of the neuromotor system that allows motor re-learning and recovery in chronic stages.

Keywords: spasticity, motor recovery, stroke, neuroplasticity, rehabilitation

\section{INTRODUCTION}

According to the CDC, approximately 800,000 people have a stroke every year in the United States. The continued care of seven million stroke survivors costs the nation approximately $\$ 38.6$ billion annually. Spasticity and weakness (i.e., spastic paresis) are the primary motor impairments and impose significant challenges for patient care. Weakness is the primary contributor to impairment in chronic stroke (1). Spasticity is present in about $20-40 \%$ stroke survivors (2). Spasticity not only has downstream effects on the patient's quality of life but also lays substantial burdens on the caregivers and society (2).

Clinically, poststroke spasticity is easily recognized as a phenomenon of velocity-dependent increase in tonic stretch reflexes ("muscle tone") with exaggerated tendon jerks, resulting from hyperexcitability of the stretch reflex (3). Though underlying mechanisms of spasticity remain poorly understood, it is well accepted that there is hyperexcitability of the stretch reflex in spasticity (4-7). Accumulated evidence from animal (8) and human studies (9-18) supports supraspinal origins of stretch reflex hyperexcitability. In particular, reticulospinal (RS) hyperexcitability resulted from loss of balanced inhibitory, and excitatory descending RS projections after stroke is the most 
plausible mechanism for poststroke spasticity (19). On the other hand, animal studies have strongly supported the possible role of RS pathways in motor recovery (20-36), while recent studies with stroke survivors have demonstrated that RS pathways may not always be beneficial $(37,38)$. The relation between spasticity and motor recovery and the role of plastic changes after stroke in this relation, particularly RS hyperexcitability, remain poorly understood among clinicians and researchers. Thus, management of spasticity and facilitation of motor recovery remain clinical challenges. This review is organized into the following sessions to understand this relation and its implication in clinical management.

- Poststroke spasticity and motor recovery are mediated by different mechanisms

- Motor recovery are mediated by cortical plastic reorganizations (spontaneous or via intervention)

- Reticulospinal hyperexcitability as a result of maladaptive plastic changes is the most plausible mechanism for spasticity

- Possible roles of RS hyperexcitability in motor recovery

- An example of spasticity reduction for facilitation of motor recovery

\section{POSTSTROKE SPASTICITY AND MOTOR RECOVERY ARE MEDIATED BY DIFFERENT MECHANISMS}

In the course of complete motor recovery, motor recovery follows a relatively predictable pattern regardless of stoke types (hemorrhagic or ischemic, cortical or subcortical) (39). Brunnstrom $(40,41)$ empirically described the stereotypical stages of motor recovery: (1) flaccidity; (2) appearance of spasticity; (3) increased spasticity with synergistic voluntary movement; (4) movement patterns out of synergy and spasticity begins to decrease; (5) more complex movements and spasticity continues to decrease; (6) spasticity disappears; and (7) full recovery of normal function with coordinated voluntary movements. Broadly speaking, there are three recovery stages: flaccid, spastic (emerging, worsening, and decreasing, stages 2-5), and recovered (voluntary control without spasticity, stages 6-7). During the course of motor recovery, stroke survivors could progress from one recovery stage to the next at variable rates, but always in an orderly fashion and without omitting any stage. However, recovery may be arrested at any one of these stages $(39,41)$. The classification of motor recovery stages is well accepted and used in clinical practice. The pattern of motor recovery and spasticity is confirmed in a recent longitudinal study in 2011 (42).

It is commonly observed that hyperreflexia and spasticity are gradually developed after stroke. There is no sudden change to hyperreflexia (43). The emergence of spasticity, though highly variable (44), is usually seen between 1 and 6 weeks after the initial injury (45). This implies that the development of poststroke spasticity is related to neuronal plastic changes within the central nervous system after the initial injury [see reviews (4-7, 45-47)]. Intensive therapy improves motor function, but has no effect on spasticity (48). A single dose of selective serotonin reuptake inhibitors (10 mg escitalopram) significantly increased spasticity (measured by reflex torque) without affecting muscle strength of spastic leg muscles after stroke (49). In contrast, another study (50) showed that cyproheptadine, an anti-serotonergic agent, helped reduction of muscle relaxation time possibly via reduction of RS excitability and spasticity reduction in the finger flexors, but without affecting muscle strength in spastic hand muscles after stroke. These findings indicate that (1) spasticity and motor recovery are mediated by different mechanisms; (2) the development of spasticity is a milestone in the course of recovery, but reflects a phenomenon of abnormal plasticity; and (3) In chronic stroke, motor recovery is arrested or plateaued. Different stages of motor recovery in chronic stroke could reflect different underlying pathophysiology in the course of motor recovery and spasticity.

\section{MOTOR RECOVERY ARE MEDIATED BY CORTICAL PLASTIC REORGANIZATIONS (SPONTANEOUS OR VIA INTERVENTION)}

Plastic reorganization occurs immediately after stroke. Following focal damage to the motor cortex and its descending pathways, the surviving portions of the brain usually undergo substantial structural and functional reorganization that occurs in the perilesional areas, as well as in the ipsilesional and contralesional cortices in an animal study (51), and human neuroimaging studies (52-66). These plastic changes reflect the capability of the brain, particularly the cerebral cortex, to alter the structure and function of neurons and their networks in response to damage caused by stroke. As such, neural plasticity provides a foundation for recovery of motor function after stroke $(67,68)$. Motor rehabilitation relies on a combination of recovery and compensation through spontaneous recovery and motor learning during rehabilitation. True motor recovery means that undamaged brain regions generate commands to the same muscles to produce the same motor patterns, while motor compensation refers to new motor patterns (different muscles) that are controlled by alternative brain areas to accomplish the task goal $(69,70)$. Longitudinal studies have shown that motor recovery from hemiparesis proceeds through a series of fairly predictable stages over the first 6 months after stroke, regardless of the type of therapeutic intervention (71). During this period, there is a process of spontaneous recovery which peaks approximately in the first 4 weeks and then tapers off over 6 months. However, this does not impose physiological limits in recovery. Through novel rehabilitation protocols and mass practice, considerable motor improvement could be realized in the chronic stages ( $>1$ year) (72). Such motor rehabilitation programs should include repetitive and task-specific practice at high intensity in a multidisciplinary environment to promote neural plasticity for motor recovery $(73,74)$. These motor training protocols could be realized by a number of novel neurorehabilitation methods, such as constraint-induced movement therapy (CIMT) $(75,76)$, robotic training (77-79), and body weight-supported treadmill training $(80,81)$. Accumulated evidence has supported the idea that the recovery-related cortical plastic reorganization and activation changes after the above training methods are used in chronic stroke $(57,82-85)$. Pharmacological agent, e.g., early 
prescription of fluoxetine, with physical therapy in the FLAME trial has shown to enhance motor recovery after stroke via modulation of spontaneous neural plasticity (86).

Both ipsilesional and contralesional motor cortices undergo plastic reorganization following a stroke, as mentioned above. Activation of bilateral sensorimotor cortices during voluntary movement of the paretic hand in stroke patients was reported (87). Activation of the contralesional hemisphere is greater in patients with poor motor function $(88,89)$, but decreases over time with motor recovery (57). Such changes result in abnormal interhemispheric interaction. Specifically, there is an abnormally high inhibitory drive from the contralesional hemisphere to the ipsilesional hemisphere (90). This abnormal interhemispheric inhibition correlates negatively with motor function in stroke patients. It is viewed as maladaptive plasticity (91). Based on the interhemispheric competition model, two main strategies of modulation of motor cortex excitability using non-invasive brain stimulation have been used to restore the balance of interhemispheric inhibition between lesioned and contralesional hemispheres, i.e., upregulation of excitability of the motor cortex of the lesioned hemisphere and downregulation of excitability of the motor cortex in the contralesional hemisphere (92). Restoration of interhemispheric inhibition via tDCS $(58,93)$ or rTMS $(59,94,95)$ has shown to facilitate recovery of motor function in stroke patients (96).

\section{RS HYPEREXCITABILITY AS A RESULT OF MALADAPTIVE PLASTIC CHANGES IS THE MOST PLAUSIBLE MECHANISM FOR SPASTICITY}

Spasticity is resulted from hyperexcitability of the stretch reflex, which is gradually developed after stroke (4-7). It is attributed to disinhibition of stretch reflexes as a result of altered descending inputs to spinal stretch reflex circuits after stroke (97). Disruption of descending supraspinal inputs after stroke could lead to plastic rearrangement at segmental levels $(4,5,7,98)$. In a recent animal study, Sist et al. (98) have demonstrated that there is a time-limited period of heightened poststroke structural plasticity in both brain and spinal cord after a sensorimotor stroke. The spinal plastic change correlates with the severity of cortical injury.

Excitability of the stretch reflex circuit (afferent fibers, spinal motor neurons, and efferent fibers) is predominantly regulated by excitatory and inhibitory descending signals of supraspinal origins $(4,6,7,99,100)$. In a neurologically intact person, the descending reticulospinal tract (RST) and vestibulospinal tract (VST) provide a balanced excitatory and inhibitory descending regulation. Other descending pathways are either not related to the spinal stretch reflex (corticospinal and tectospinal) $(6,8$, 100 ) or absent in humans (rubrospinal tract) (101). Dorsal RST descends in parallel with CST in the dorsolateral funiculus and provides a dominant inhibitory effect on the spinal stretch reflex, while medial RST and VST descend in the ventromedial cord, providing excitatory inputs. It is important to note that dorsal RST receives facilitation from the motor cortex via corticoreticular projections, which run in close proximity with the corticospinal tract. In stroke with cortical and internal capsular lesions, damages often happen to both CST and corticoreticular tracts due to their anatomical proximity, resulting in loss of cortical facilitatory input to the medullary inhibitory center, thus less inhibition from dorsal RST. This leaves the facilitatory medial RST and VST unopposed, since they are independent of cortical control, thus the stretch reflex hyperexcitability [see Figure 2 in Ref. (19)]. This mechanism could also explain why a stereotyped pattern of spasticity is observed regardless of affected areas (cortical or subcortical stroke).

There is experimental evidence from animal and human studies to support the important role of RST in spasticity [reviewed in Ref. $(6,8,100)]$. For example, surgical section of unilateral or bilateral VST in the anterior cord has little effect (102) or a transient effect (103) on spasticity. With more extensive cordotomies that damaged the medial RST, spasticity was drastically reduced (103). Given unilateral nature of vestibulospinal projections (104), the role of VST in spasticity was recently tested in chronic stroke (105). Vestibular-evoked myogenic potentials in the sternocleidomastoid muscle in response to high-level acoustic stimuli $(130 \mathrm{~dB})$ to the ears of stroke survivors were greater on the impaired side than the non-impaired side. There existed a strong positive relationship between the degree of asymmetry and the overall severity of spasticity from upper and lower limbs in spastic-paretic stroke survivors. The findings thus suggest a possible role of hyperexcitability of VST in poststroke spasticity (105). Yet, this level of acoustic stimuli is also likely to activate RS pathways via acoustic startle reflex (ASR) $(106,107)$.

Acoustic startle reflex has been used to examine RS excitability non-invasively in stroke survivors $(17,18,108-111)$. In stroke survivors with cerebral infarcts normal, ASR responses could be elicited in flaccid muscles in the acute phase, although no muscle response to magnetic cortical stimulation of the primary motor cortex was elicited in these subjects (108). This suggests that the circuit of ASR remained intact in these patients. In chronic stroke, exaggerated ASR responses were observed in spastic muscles (109), indicating increased RS excitability. In a recent study (17, 18), ASR responses were examined in chronic stroke at different stages of motor recovery (flaccid, spastic, and recovered). Exaggerated ASR responses were observed only in spastic biceps muscles. Since motor recovery has been arrested in chronic stage, such findings support the important role of RS hyperexcitability in mediating poststroke spasticity. Given its role in maintaining joint position and posture against gravity (112), RS hyperexcitability and its anti-gravity effect is expected to lead to a new neuromuscular balance, reflecting a shift in reference configuration after stroke $(113,114)$. This new balance could be reflected by a change in the resting angle of a joint. Bhadane et al. recently found that there were strong correlations between the resting angle of the elbow joint and severity of spasticity as reflected by clinical (MAS and Tardieu R1 angle) and biomechanical (reflex torque) measurements (115). Pharmacological agents acting on serotonin, the primary neurotransmitter for RS pathways, could either increase (49) or decrease (50) spasticity. Collectively, emerging evidence supports the important role of RS hyperexcitability in poststroke spasticity. 


\section{POSSIBLE ROLES OF RS HYPEREXCITABILITY IN MOTOR RECOVERY}

Contributions to motor recovery from ipsilesional and contralesional cortical reorganization through spontaneous recovery and facilitation and modulation of cortical plasticity are well recognized, as stated above. In contrast, RS hyperexcitability has been viewed consistently to play a major role in spasticity from both animal and human studies. The role of neural plasticity at the subcortical and bulbospinal pathways in motor recovery has been suggested from animal studies but remains controversial in human studies. In general, recovery of motor function after stroke depends on structural integrity, including both CST and RST (66, 116-118).

Findings from recent animal studies suggest the potential role of existing descending bulbospinal pathways, particularly RS projections to spinal interneurons and motoneurons (23, 26-29, 36). Riddle and Baker (29) reported that RS (descending from medial brainstem) and corticospinal pathways descended in parallel and had largely overlapping effects on spinal interneurons and motoneurons; importantly, responses from spinal motoneurons to stimulation of either pathway at supraspinal levels were of similar amplitudes during a reach and grasp task. The findings suggest the important role of RST in the distal limb muscles, in addition to its known contribution to proximal limb muscles (30). Buford and colleagues also reported significant RS contributions to motor output (35) and motor recovery (36). The rubrospinal tract descending from the lateral brainstem is almost absent in humans (101). In the context of damage to M1 and/or corticospinal pathways, strengthening the existing intact RS projections is thus plausible to compensate for the damage as demonstrated in these animal models $(29,32,33,35,36)$.

The possible role of RS pathways in motor recovery after the corticospinal (CST) damage as result of a stroke in humans has been controversial $(37,38)$. Recently, Byblow and colleagues recommended that the importance of the cortico-reticulo-spinal pathway needs to be considered before using non-invasive brain stimulation to suppress contralesional motor cortex excitability because it may contribute to motor recovery, particularly in patients with severe paresis (37). However, they agreed with previous reports $(58,59,62,63)$ that suppression of contralesional cortical excitability is beneficial for those with less motor impairment. This view is further supported by findings of another recent study (38). Auditory stimulation improves motor performance of wrist extension in chronic stroke patients with spasticity and severe paresis (spastic paresis), but not in patients with more spasticity and relatively less paresis (spastic co-contraction) or with minimal paresis. The main mechanism is thought to be stimulation of RS pathway via auditory stimulation $(38,119,120)$. Taken together, these studies in stroke survivors suggest that RS hyperexcitability and spasticity are phenomena of maladaptive changes in the course of motor recovery (19), and the role of RS hyperexcitability depends on the severity of motor impairments.
The findings (38) further suggest that RS pathway plays different roles at different stages of motor recovery, likely because of its potential role in spasticity after stroke. Individualized rehabilitation protocols utilizing RS pathways could be developed to facilitate motor recovery in some patients. In patients with severe motor impairment and spasticity, RS pathway activation via auditory stimulation training (38) may contribute to gross motor strength via synergistic activation (121), thus improving motor performance. However, such synergistic activation is not likely to improve performance of isolated wrist extension in patients with spastic co-contraction in both wrist flexors and extensors or in patients without spasticity (38). Furthermore, motor recovery after stroke follows a predictable pattern, from flaccid to spastic and to recovered stages. Auditory stimulation training via activation of the RS pathway (rhythmic cueing, music therapy, etc.) (38, 122-125) may be recommended for use in patients with severe motor impairment and in acute and subacute phases; as such, this intervention could potentially facilitate the progress of motor recovery after stroke, i.e., moving through the recovery stages faster in some patients.

\section{AN EXAMPLE OF SPASTICITY REDUCTION FOR FACILITATION OF MOTOR RECOVERY}

Spasticity is an important milestone in the course of motor recovery. It emerges and disappears as the recovery progresses. In chronic stroke when motor recovery is plateaued or arrested, e.g., spastic stages (Brunnstrom stages 2-5), spasticity usually leads to synergistic patterns of abnormal movement and impaired motor control $(39,41,126)$. A stroke survivor actually flexes the fingers in an attempt of voluntary finger extension, due to abnormal co-activation of spastic finger flexors overriding weak finger extensor muscles (127). In a study examining arm pointing movements to different targets on a horizontal surface, Levin reported that stroke subjects with severe spasticity were able to plan and move the arm to all parts of available workspace, but their actual movement was deviated from smooth straight lines with increased dispersion and segmentation (128). The results demonstrate deficits in inter-joint coordination of activation of spastic muscles in spastic stroke survivors. Hemiplegic stroke survivors could accurately perceive and reproduce a force within a limb either by the spastic-paretic limb or contralateral limb (129). Force produced by one limb could not be accurately perceived by the contralateral limb in hemiplegic stroke survivors (130). Interactions between two limbs are altered (17, $18,131)$. Impaired motor control in spastic stroke survivors is related to spontaneous firing of motor units and involuntary control of activation of spastic muscles $(13,14,16)$, possibly caused by RS hyperexcitability (19). On the other hand, it is also important to point out that spasticity could be beneficial in the lower extremity. For example, spasticity in quadriceps may help stabilize the knee joint during the stance phase and thus help transfers.

Understanding of these two separate mechanisms underlying motor recovery and spasticity and of the role of spasticity in 
impaired motor control is critical for its successful management. Aggressive management of spasticity with botulinum toxin (BoNT) in carefully selected muscles can purposefully reduce involuntary activation of spastic muscles, thus to improve voluntary control of movement and motor function. BoNT blocks the release of acetylcholine presynaptically at the neuromuscular junction and transiently weakens the muscle (132). BoNT injection induces synapse plasticity of muscular afferents and generates synaptic plastic reorganization at spinal motor neurons and interneuron system and beyond. As such, the central effect of BoNT therapy converts the neuromotor system into a transient labile state (133). This allows regrowth or strengthening of appropriate synapses and suppression of inappropriate ones, i.e., neural plasticity and motor re-learning, if coupled with sustained activity-based, goal-oriented training programs (134). This is particularly important for motor recovery in chronic stroke when motor recovery is usually plateaued or arrested. For example, injection of BoNT to spastic finger flexors weakens grip strength as expected, however, the patient is able to release her grip better with decreased co-activation from finger flexors and, therefore, to engage the spastic-paretic hand more in bimanual tasks (135). Similarly, suppression of involuntary activation of periscapular muscles improves arm function and thus activities of daily living (136). This concept of "therapeutic weakness" is further supported by a recent study (137). After BoNT injection to elbow, wrist, and finger flexors, spastic hemiparetic stroke survivors are able to perform reaching (elbow and wrist extension) tasks better. The authors have attributed this functional improvement to better voluntary control of antagonists (extensors), despite of weakness of injected flexors.

\section{REFERENCES}

1. Kamper DG, Fischer HC, Cruz EG, Rymer WZ. Weakness is the primary contributor to finger impairment in chronic stroke. Arch Phys Med Rehabil (2006) 87:1262. doi:10.1016/j.apmr.2006.05.013

2. Zorowitz RD, Gillard PJ, Brainin M. Poststroke spasticity: sequelae and burden on stroke survivors and caregivers. Neurology (2013) 80:S45-52. doi:10.1212/WNL.0b013e3182764c86

3. Lance JW. Symposium synopsis. In: Feldman RG, Young RR, Koella WP, editors. Spasticity: Disordered Motor Control. Chicago, IL: Year Book Medical Publishers (1980). p. 485-94.

4. Gracies JM. Pathophysiology of spastic paresis. II: emergence of muscle overactivity. Muscle Nerve (2005) 31:552-71. doi:10.1002/mus.20285

5. Nielsen JB, Crone C, Hultborn H. The spinal pathophysiology of spasticity - from a basic science point of view. Acta Physiol (2007) 189:171-80. doi:10.1111/j.1748-1716.2006.01652.x

6. Mukherjee A, Chakravarty A. Spasticity mechanisms - for the clinician. Front Neurol (2010) 1:149. doi:10.3389/fneur.2010.00149

7. Burke D, Wissel J, Donnan GA. Pathophysiology of spasticity in stroke. Neurology (2013) 80:S20-6. doi:10.1212/WNL.0b013e31827624a7

8. Brown P. Pathophysiology of spasticity. J Neurol Neurosurg Psychiatry (1994) 57:773-7. doi:10.1136/jnnp.57.7.773

9. Katz RT, Rymer WZ. Spastic hypertonia: mechanisms and measurement. Arch Phys Med Rehabil (1989) 70:144-55.

10. Burne JA, Carleton VL, O'Dwyer NJ. The spasticity paradox: movement disorder or disorder of resting limbs? J Neurol Neurosurg Psychiatry (2005) 76:47-54. doi:10.1136/jnnp.2003.034785

11. Li S, Kamper DG, Rymer WZ. Effects of changing wrist positions on finger flexor hypertonia in stroke survivors. Muscle Nerve (2006) 33:183-90. doi:10.1002/mus.20453

\section{CONCLUDING REMARKS}

Neural plasticity is an important process mediating substantial recovery of motor function after stroke. However, some changes may be maladaptive. The RS hyperexcitability is the most plausible mechanism for spasticity, while recovery of strength and motor function is mainly related to cortical reorganization. It is important to differentiate and understand that motor recovery and spasticity have different mechanisms. Facilitation and modulation of neural plasticity through rehabilitative strategies, such as early interventions with repetitive goal-oriented intensive therapy, appropriate non-invasive brain stimulation, and pharmacological agents are the keys to promote motor recovery after stroke. Individualized rehabilitation protocols could be developed to utilize or avoid the maladaptive plasticity, such as RS hyperexcitability in the course of motor recovery. Aggressive and appropriate spasticity management with BoNT therapy is an example of how to create a transient plastic state of the neuromotor system that allows motor re-learning and recovery in chronic stages.

\section{AUTHOR CONTRIBUTIONS}

The author confirms being the sole contributor of this work and approved it for publication.

\section{ACKNOWLEDGMENTS}

This work was supported in part by an NIH grant R21HD08712801. The author thanks Mike Green D.O., and Ana DurandSanchez, M.D. for helpful suggestions and editorial changes.

12. Kallenberg LA, Hermens HJ. Motor unit properties of biceps brachii in chronic stroke patients assessed with high-density surface EMG. Muscle Nerve (2009) 39:177-85. doi:10.1002/mus.21090

13. Mottram CJ, Suresh NL, Heckman CJ, Gorassini MA, Rymer WZ. Origins of abnormal excitability in biceps brachii motoneurons of spastic-paretic stroke survivors. J Neurophysiol (2009) 102:2026-38. doi:10.1152/jn.00151.2009

14. Mottram CJ, Wallace CL, Chikando CN, Rymer WZ. Origins of spontaneous firing of motor units in the spastic-paretic biceps brachii muscle of stroke survivors. J Neurophysiol (2010) 104:3168-79. doi:10.1152/jn.00463.2010

15. Kallenberg LA, Hermens HJ. Motor unit properties of biceps brachii during dynamic contractions in chronic stroke patients. Muscle Nerve (2011) 43:112-9. doi:10.1002/mus.21803

16. Chang SH, Francisco GE, Zhou P, Rymer WZ, Li S. Spasticity, weakness, force variability, and sustained spontaneous motor unit discharges of resting spastic-paretic biceps brachii muscles in chronic stroke. Muscle Nerve (2013) 48:85-92. doi:10.1002/mus.23699

17. Li S, Chang SH, Francisco GE, Verduzco-Gutierrez M. Acoustic startle reflex in patients with chronic stroke at different stages of motor recovery: a pilot study. Top Stroke Rehabil (2014) 21:358-70. doi:10.1310/tsr2104-358

18. Li S, Durand-Sanchez A, Latash ML. Inter-limb force coupling is resistant to distorted visual feedback in chronic hemiparetic stroke. J Rehabil Med (2014) 46:206-11. doi:10.2340/16501977-1256

19. Li S, Francisco G. New insights into the pathophysiology of post-stroke spasticity. Front Hum Neurosci (2015) 9:192. doi:10.3389/fnhum.2015.00192

20. Buford JA, Davidson AG. Movement-related and preparatory activity in the reticulospinal system of the monkey. Exp Brain Res (2004) 159:284-300. doi:10.1007/s00221-004-1956-4

21. Buford JF, Robertson E, Williams PC. Meharry Medical College School of Medicine. Acad Med (2004) 79:S98-101. doi:10.1097/00001888-20040700100023 
22. Davidson AG, Buford JA. Motor outputs from the primate reticular formation to shoulder muscles as revealed by stimulus-triggered averaging. J Neurophysiol (2004) 92:83-95. doi:10.1152/jn.00083.2003

23. Davidson AG, Buford JA. Bilateral actions of the reticulospinal tract on arm and shoulder muscles in the monkey: stimulus triggered averaging. Exp Brain Res (2006) 173:25-39. doi:10.1007/s00221-006-0374-1

24. Banks JJ, Lavender SA, Buford JA, Sommerich CM. Measuring pad-pad pinch strength in a non-human primate: Macaca fascicularis. J Electromyogr Kinesiol (2007) 17:725-30. doi:10.1016/j.jelekin.2006.07.009

25. Davidson AG, Schieber MH, Buford JA. Bilateral spike-triggered average effects in arm and shoulder muscles from the monkey pontomedullary reticular formation. JNeurosci (2007) 27:8053-8. doi:10.1523/ JNEUROSCI.0040-07.2007

26. Riddle CN, Edgley SA, Baker SN. Direct and indirect connections with upper limb motoneurons from the primate reticulospinal tract. J Neurosci (2009) 29:4993-9. doi:10.1523/JNEUROSCI.3720-08.2009

27. Sakai ST, Davidson AG, Buford JA. Reticulospinal neurons in the pontomedullary reticular formation of the monkey (Macaca fascicularis). Neuroscience (2009) 163:1158-70. doi:10.1016/j.neuroscience.2009.07.036

28. Herbert WJ, Davidson AG, Buford JA. Measuring the motor output of the pontomedullary reticular formation in the monkey: do stimulus-triggered averaging and stimulus trains produce comparable results in the upper limbs? Exp Brain Res (2010) 203:271-83. doi:10.1007/s00221-010-2231-5

29. Riddle CN, Baker SN. Convergence of pyramidal and medial brain stem descending pathways onto macaque cervical spinal interneurons. J Neurophysiol (2010) 103:2821-32. doi:10.1152/jn.00491.2009

30. Baker SN. The primate reticulospinal tract, hand function and functional recovery. J Physiol (2011) 589:5603-12. doi:10.1113/jphysiol.2011.215160

31. Fisher KM, Zaaimi B, Baker SN. Reticular formation responses to magnetic brain stimulation of primary motor cortex. J Physiol (2012) 590:4045-60. doi:10.1113/jphysiol.2011.226209

32. Zaaimi B, Edgley SA, Soteropoulos DS, Baker SN. Changes in descending motor pathway connectivity after corticospinal tract lesion in macaque monkey. Brain (2012) 135:2277-89. doi:10.1093/brain/aws115

33. Fisher KM, Chinnery PF, Baker SN, Baker MR. Enhanced reticulospinal output in patients with (REEP1) hereditary spastic paraplegia type 31. J Neurol (2013) 260:3182-4. doi:10.1007/s00415-013-7178-6

34. Montgomery LR, Herbert WJ, Buford JA. Recruitment of ipsilateral and contralateral upper limb muscles following stimulation of the cortical motor areas in the monkey. Exp Brain Res (2013) 230:153-64. doi:10.1007/ s00221-013-3639-5

35. Ortiz-Rosario A, Berrios-Torres I, Adeli H, Buford JA. Combined corticospinal and reticulospinal effects on upper limb muscles. Neurosci Lett (2014) 561:30-4. doi:10.1016/j.neulet.2013.12.043

36. Herbert WJ, Powell K, Buford JA. Evidence for a role of the reticulospinal system in recovery of skilled reaching after cortical stroke: initial results from a model of ischemic cortical injury. Exp Brain Res (2015) 233:3231-51. doi:10.1007/s00221-015-4390-x

37. Bradnam LV, Stinear CM, Byblow WD. Ipsilateral motor pathways after stroke: implications for noninvasive brain stimulation. Front Hum Neurosci (2013) 7:184. doi:10.3389/fnhum.2013.00184

38. Aluru V, Lu Y, Leung A, Verghese J, Raghavan P. Effect of auditory constraints on motor learning depends on stage of recovery post stroke. Front Neurol (2014) 5:106. doi:10.3389/fneur.2014.00106

39. Twitchell TE. The restoration of motor function following hemiplegia in man. Brain (1951) 74:443-8. doi:10.1093/brain/74.4.443

40. Brunnstrom S. Motor testing procedures in hemiplegia: based on sequential recovery stages. Phys Ther (1966) 46:357-75.

41. Brunnstrom S. Movement Therapy in Hemiplagia. A Neurophysiological Approach. New York, NY: Harper \& Row (1970).

42. Malhotra S, Pandyan AD, Rosewilliam S, Roffe C, Hermens H. Spasticity and contractures at the wrist after stroke: time course of development and their association with functional recovery of the upper limb. Clin Rehabil (2011) 25:184-91. doi:10.1177/0269215510381620

43. Farmer SF, Harrison LM, Ingram DA, Stephens JA. Plasticity of central motor pathways in children with hemiplegic cerebral palsy. Neurology (1991) 41:1505-10. doi:10.1212/WNL.41.9.1505

44. Ward AB. A literature review of the pathophysiology and onset of post-stroke spasticity. Eur J Neurol (2012) 19:21-7. doi:10.1111/j.1468-1331.2011.03448.x
45. Balakrishnan S, Ward AB. The diagnosis and management of adults with spasticity. Handb Clin Neurol (2013) 110:145-60. doi:10.1016/ B978-0-444-52901-5.00013-7

46. Gracies JM. Pathophysiology of spastic paresis. I: paresis and soft tissue changes. Muscle Nerve (2005) 31:535-51. doi:10.1002/mus.20284

47. Nudo RJ. Mechanisms for recovery of motor function following cortical damage. Curr Opin Neurobiol (2006) 16:638-44. doi:10.1016/j.conb.2006. 10.004

48. Zondervan DK, Augsburger R, Bodenhoefer B, Friedman N, Reinkensmeyer DJ, Cramer SC. Machine-based, self-guided home therapy for individuals with severe arm impairment after stroke: a randomized controlled trial. Neurorehabil Neural Repair (2015) 29:395-406. doi:10.1177/ 1545968314550368

49. Gourab K, Schmit BD, Hornby TG. Increased lower limb spasticity but not strength or function following a single-dose serotonin reuptake inhibitor in chronic stroke. Arch Phys Med Rehabil (2015) 96:2112-9. doi:10.1016/ j.apmr.2015.08.431

50. Seo NJ, Fischer HW, Bogey RA, Rymer WZ, Kamper DG. Effect of a serotonin antagonist on delay in grip muscle relaxation for persons with chronic hemiparetic stroke. Clin Neurophysiol (2011) 122:796-802. doi:10.1016/ j.clinph.2010.10.035

51. Nudo RJ, Wise BM, SiFuentes F, Milliken GW. Neural substrates for the effects of rehabilitative training on motor recovery after ischemic infarct. Science (1996) 272:1791-4. doi:10.1126/science.272.5269.1791

52. Palmer E, Ashby P, Hajek VE. Ipsilateral fast corticospinal pathways do not account for recovery in stroke. Ann Neurol (1992) 32:519-25. doi:10.1002/ ana. 410320407

53. Weiller C, Ramsay SC, Wise RJ, Friston KJ, Frackowiak RS. Individual patterns of functional reorganization in the human cerebral cortex after capsular infarction. Ann Neurol (1993) 33:181-9. doi:10.1002/ana. 410330208

54. Turton A, Wroe S, Trepte N, Fraser C, Lemon RN. Contralateral and ipsilateral EMG responses to transcranial magnetic stimulation during recovery of arm and hand function after stroke. Electroencephalogr Clin Neurophysiol (1996) 101:316-28. doi:10.1016/0924-980X(96)95560-5

55. Pineiro R, Pendlebury S, Johansen-Berg H, Matthews PM. Functional MRI detects posterior shifts in primary sensorimotor cortex activation after stroke: evidence of local adaptive reorganization? Stroke (2001) 32:1134-9. doi:10.1161/01.STR.32.5.1134

56. Maier MA, Armand J, Kirkwood PA, Yang HW, Davis JN, Lemon RN. Differences in the corticospinal projection from primary motor cortex and supplementary motor area to macaque upper limb motoneurons: an anatomical and electrophysiological study. Cereb Cortex (2002) 12:281-96. doi:10.1093/cercor/12.3.281

57. Ward NS, Brown MM, Thompson AJ, Frackowiak RS. Neural correlates of motor recovery after stroke: a longitudinal fMRI study. Brain (2003) 126:2476-96. doi:10.1093/brain/awg145

58. Fregni F, Boggio PS, Mansur CG, Wagner T, Ferreira MJ, Lima MC, et al. Transcranial direct current stimulation of the unaffected hemisphere in stroke patients. Neuroreport (2005) 16:1551-5. doi:10.1097/01. wnr.0000177010.44602.5e

59. Mansur CG, Fregni F, Boggio PS, Riberto M, Gallucci-Neto J, Santos $\mathrm{CM}$, et al. A sham stimulation-controlled trial of rTMS of the unaffected hemisphere in stroke patients. Neurology (2005) 64:1802-4. doi:10.1212/ 01.WNL.0000161839.38079.92

60. Boudrias MH, Belhaj-Saif A, Park MC, Cheney PD. Contrasting properties of motor output from the supplementary motor area and primary motor cortex in rhesus macaques. Cereb Cortex (2006) 16:632-8. doi:10.1093/cercor/ bhj009

61. Kim YH, You SH, Kwon YH, Hallett M, Kim JH, Jang SH. Longitudinal fMRI study for locomotor recovery in patients with stroke. Neurology (2006) 67:330-3. doi:10.1212/01.wnl.0000225178.85833.0d

62. Boggio PS, Nunes A, Rigonatti SP, Nitsche MA, Pascual-Leone A, Fregni F. Repeated sessions of noninvasive brain DC stimulation is associated with motor function improvement in stroke patients. Restor Neurol Neurosci (2007) 25:123-9.

63. Dafotakis M, Grefkes C, Eickhoff SB, Karbe H, Fink GR, Nowak DA. Effects of rTMS on grip force control following subcortical stroke. Exp Neurol (2008) 211:407-12. doi:10.1016/j.expneurol.2008.02.018 
64. Ward NS, Swayne OB, Newton JM. Age-dependent changes in the neural correlates of force modulation: an fMRI study. Neurobiol Aging (2008) 29:1434-46. doi:10.1016/j.neurobiolaging.2007.04.017

65. Bestmann S, Swayne O, Blankenburg F, Ruff CC, Teo J, Weiskopf N, et al. The role of contralesional dorsal premotor cortex after stroke as studied with concurrent TMS-fMRI. J Neurosci (2010) 30:11926-37. doi:10.1523/ JNEUROSCI.5642-09.2010

66. Madhavan S, Krishnan C, Jayaraman A, Rymer WZ, Stinear JW. Corticospinal tract integrity correlates with knee extensor weakness in chronic stroke survivors. Clin Neurophysiol (2011) 122:1588-94. doi:10.1016/j.clinph.2011. 01.011

67. Dimyan MA, Cohen LG. Neuroplasticity in the context of motor rehabilitation after stroke. Nat Rev Neurol (2011) 7:76-85. doi:10.1038/nrneurol. 2010.200

68. Pekna M, Pekny M, Nilsson M. Modulation of neural plasticity as a basis for stroke rehabilitation. Stroke (2012) 43:2819-28. doi:10.1161/ STROKEAHA.112.654228

69. Krakauer JW. Motor learning: its relevance to stroke recovery and neurorehabilitation. Curr Opinion Neurol (2006) 19:84. doi:10.1097/ 01.wco.0000200544.29915.cc

70. Levin MF, Kleim JA, Wolf SL. What do motor "recovery" and "compensation" mean in patients following stroke? Neurorehabil Neural Repair (2009) 23:313-9. doi:10.1177/1545968308328727

71. Kwakkel G, Kollen B, Lindeman E. Understanding the pattern of functional recovery after stroke: facts and theories. Restor Neurol Neurosci (2004) 22:281-99.

72. Page SJ, Gater DR, Bach YRP. Reconsidering the motor recovery plateau in stroke rehabilitation. Arch Phys Med Rehabil (2004) 85:1377-81. doi:10.1016/ j.apmr.2003.12.031

73. Langhorne P, Coupar F, Pollock A. Motor recovery after stroke: a systematic review. Lancet Neurol (2009) 8:741-54. doi:10.1016/S1474-4422(09) 70150-4

74. Takeuchi N, Izumi S. Rehabilitation with poststroke motor recovery: a review with a focus on neural plasticity. Stroke Res Treat (2013) 2013:128641. doi:10.1155/2013/128641

75. Miltner WH, Bauder H, Sommer M, Dettmers C, Taub E. Effects of constraint-induced movement therapy on patients with chronic motor deficits after stroke: a replication. Stroke (1999) 30:586-92. doi:10.1161/ 01.STR.30.3.586

76. Wolf SL, Winstein CJ, Miller JP, Taub E, Uswatte G, Morris D, et al. Effect of constraint-induced movement therapy on upper extremity function 3 to 9 months after stroke: the EXCITE randomized clinical trial. JAMA (2006) 296:2095-104. doi:10.1001/jama.296.17.2095

77. Krebs HI, Hogan N, Aisen ML, Volpe BT. Robot-aided neurorehabilitation. IEEE Trans Rehabil Eng (1998) 6:75-87. doi:10.1109/86.662623

78. Volpe BT, Krebs HI, Hogan N, Edelsteinn L, Diels CM, Aisen ML. Robot training enhanced motor outcome in patients with stroke maintained over 3 years. Neurology (1999) 53:1874-6. doi:10.1212/WNL.53.8.1874

79. Krebs HI, Mernoff S, Fasoli SE, Hughes R, Stein J, Hogan N. A comparison of functional and impairment-based robotic training in severe to moderate chronic stroke: a pilot study. NeuroRehabilitation (2008) 23:81-7.

80. Hesse S, Werner C, Bardeleben A, Barbeau H. Body weight-supported treadmill training after stroke. Curr Atheroscler Rep (2001) 3:287-94. doi:10.1007/ s11883-001-0021-z

81. Hoyer E, Jahnsen R, Stanghelle JK, Strand LI. Body weight supported treadmill training versus traditional training in patients dependent on walking assistance after stroke: a randomized controlled trial. Disabil Rehabil (2012) 34:210-9. doi:10.3109/09638288.2011.593681

82. Liepert J, Bauder H, Wolfgang HR, Miltner WH, Taub E, Weiller C. Treatment-induced cortical reorganization after stroke in humans. Stroke (2000) 31:1210-6. doi:10.1161/01.STR.31.6.1210

83. Levy CE, Nichols DS, Schmalbrock PM, Keller P, Chakeres DW. Functional MRI evidence of cortical reorganization in upper-limb stroke hemiplegia treated with constraint-induced movement therapy. Am J Phys Med Rehabil (2001) 80:4-12. doi:10.1097/00002060-200101000-00003

84. Miyai I, Suzuki M, Hatakenaka M, Kubota K. Effect of body weight support on cortical activation during gait in patients with stroke. Exp Brain Res (2006) 169:85-91. doi:10.1007/s00221-005-0123-x
85. Takahashi CD, Der-Yeghiaian L, Le V, Motiwala RR, Cramer SC. Robot-based hand motor therapy after stroke. Brain (2008) 131:425-37. doi:10.1093/ brain/awm311

86. Chollet F, Tardy J, Albucher JF, Thalamas C, Berard E, Lamy C, et al. Fluoxetine for motor recovery after acute ischaemic stroke (FLAME): a randomised placebo-controlled trial. Lancet Neurol (2011) 10:123-30. doi:10.1016/ S1474-4422(10)70314-8

87. Chollet F, DiPiero V, Wise RJ, Brooks DJ, Dolan RJ, Frackowiak RS. The functional anatomy of motor recovery after stroke in humans: a study with positron emission tomography. Ann Neurol (1991) 29:63-71. doi:10.1002/ ana. 410290112

88. Cramer SC, Nelles G, Benson RR, Kaplan JD, Parker RA, Kwong KK, et al. A functional MRI study of subjects recovered from hemiparetic stroke. Stroke (1997) 28:2518-27. doi:10.1161/01.STR.28.12.2518

89. Netz J, Lammers T, Homberg V. Reorganization of motor output in the non-affected hemisphere after stroke. Brain (1997) 120:1579-86. doi:10.1093/ brain/120.9.1579

90. Murase N, Duque J, Mazzocchio R, Cohen LG. Influence of interhemispheric interactions on motor function in chronic stroke. Ann Neurol (2004) 55:400-9. doi:10.1002/ana.10848

91. Takeuchi N, Izumi SI. Maladaptive plasticity for motor recovery after stroke: mechanisms and approaches. Neural Plast (2012) 2012:359728. doi:10.1155/2012/359728

92. Hummel FC, Cohen LG. Non-invasive brain stimulation: a new strategy to improve neurorehabilitation after stroke? Lancet Neurol (2006) 5:708-12. doi:10.1016/S1474-4422(06)70525-7

93. Hummel F, Celnik P, Giraux P, Floel A, Wu WH, Gerloff C, et al. Effects of non-invasive cortical stimulation on skilled motor function in chronic stroke. Brain (2005) 128:490-9. doi:10.1093/brain/awh369

94. Takeuchi N, Chuma T, Matsuo Y, Watanabe I, Ikoma K. Repetitive transcranial magnetic stimulation of contralesional primary motor cortex improves hand function after stroke. Stroke (2005) 36:2681-6. doi:10.1161/ 01.STR.0000189658.51972.34

95. Nowak DA, Grefkes C, Dafotakis M, Eickhoff S, Kust J, Karbe H, et al. Effects of low-frequency repetitive transcranial magnetic stimulation of the contralesional primary motor cortex on movement kinematics and neural activity in subcortical stroke. Arch Neurol (2008) 65:741-7. doi:10.1001/ archneur.65.6.741

96. Nowak DA, Grefkes C, Ameli M, Fink GR. Interhemispheric competition after stroke: brain stimulation to enhance recovery of function of the affected hand. Neurorehabil Neural Repair (2009) 23:641-56. doi:10.1177/1545968309336661

97. Lance JW. Pathophysiology of spasticity and clinical experience with baclofen. In: Feldman RG, Young RR, Koella WP, editors. Spasticity: Disordered Motor Control. Chicago, IL: Year Book Medical Publishers (1980). p. 185-203.

98. Sist B, Fouad K, Winship IR. Plasticity beyond peri-infarct cortex: spinal up regulation of structural plasticity, neurotrophins, and inflammatory cytokines during recovery from cortical stroke. Exp Neurol (2014) 252:47-56. doi:10.1016/j.expneurol.2013.11.019

99. Young RR. Spasticity: a review. Neurology (1994) 44:S12-20.

100. Sheean G. Neurophysiology of spasticity. 2nd ed. In: Barnes MP, Johnson GR, editors. Upper Motor Neurone Syndrome and Spasticity: Clinical Management and Neurophysiology. Cambridge: Cambridge University Press (2008). p. 9-63.

101. Nathan PW, Smith MC. Long descending tracts in man. I. Review of present knowledge. Brain (1955) 78:248-303. doi:10.1093/brain/78.2.248

102. Schreiner LH, Lindsley DB, Magoun HW. Role of brain stem facilitatory systems in maintenance of spasticity. J Neurophysiol (1949) 12:207-16.

103. Bucy PC. Studies on the human neuromuscular mechanism. II. Effect of ventromedial cordotomy on muscular spasticity in man. Arch Neurol Psychiatry (1938) 40:639-62. doi:10.1001/archneurpsyc.1938.02270100011001

104. Nyberg-Hansen R. Origin and termination of fibers from the vestibular nuclei descending in the medial longitudinal fasciculus. An experimental study with silver impregnation methods in the cat. J Comp Neurol (1964) 122:355-67. doi:10.1002/cne.901220307

105. Miller DM, Klein CS, Suresh NL, Rymer WZ. Asymmetries in vestibular evoked myogenic potentials in chronic stroke survivors with spastic 
hypertonia: evidence for a vestibulospinal role. Clin Neurophysiol (2014) 125(10):2070-8. doi:10.1016/j.clinph.2014.01.035

106. Davis M, Gendelman DS, Tischler MD, Gendelman PM. A primary acoustic startle circuit: lesion and stimulation studies. J Neurosci (1982) 2:791.

107. Brown P, Rothwell JC, Thompson PD, Britton TC, Day BL, Marsden CD. New observations on the normal auditory startle reflex in man. Brain (1991) 114(Pt 4):1891-902. doi:10.1093/brain/114.4.1891

108. Voordecker P, Mavroudakis N, Blecic S, Hildebrand J, Zegers de Beyl D. Audiogenic startle reflex in acute hemiplegia. Neurology (1997) 49:470-3. doi:10.1212/WNL.49.2.470

109. Jankelowitz SK, Colebatch JG. The acoustic startle reflex in ischemic stroke. Neurology (2004) 62:114-6. doi:10.1212/01.WNL.0000101711.48946.35

110. Coombes SA, Janelle CM, Cauraugh JH. Chronic stroke and aging: the impact of acoustic stimulus intensity on fractionated reaction time. Neurosci Lett (2009) 452:151. doi:10.1016/j.neulet.2009.01.041

111. Honeycutt CF, Perreault EJ. Planning of ballistic movement following stroke: insights from the startle reflex. PLoS One (2012) 7:e43097. doi:10.1371/ journal.pone.0043097

112. Drew T, Prentice S, Schepens B. Cortical and brainstem control of locomotion. Prog Brain Res (2004) 143:251-61. doi:10.1016/S0079-6123(03) 43025-2

113. Calota A, Feldman AG, Levin MF. Spasticity measurement based on tonic stretch reflex threshold in stroke using a portable device. Clin Neurophysiol (2008) 119:2329-37. doi:10.1016/j.clinph.2008.07.215

114. Calota A, Levin MF. Tonic stretch reflex threshold as a measure of spasticity: implications for clinical practice. Top Stroke Rehabil (2009) 16:177-88. doi:10.1310/tsr1603-177

115. Bhadane MY, Gao F, Francisco GE, Zhou P, Li S. Correlation of resting elbow angle with spasticity in chronic stroke survivors. Front Neurol (2015) 6:183. doi:10.3389/fneur.2015.00183

116. Stinear C. Prediction of recovery of motor function after stroke. Lancet Neurol (2010) 9:1228-32. doi:10.1016/S1474-4422(10)70247-7

117. Byblow WD, Stinear CM, Barber PA, Petoe MA, Ackerley SJ. Proportional recovery after stroke depends on corticomotor integrity. Ann Neurol (2015) 78:848-59. doi:10.1002/ana.24472

118. Schulz R, Wessel MJ, Zimerman M, Timmermann JE, Gerloff C, Hummel FC. White matter integrity of specific dentato-thalamo-cortical pathways is associated with learning gains in precise movement timing. Cereb Cortex (2015) 25:1707-14. doi:10.1093/cercor/bht356

119. Paltsev YI, Elner AM. Change in the functional state of the segmental apparatus of the spinal cord under the influence of sound stimuli and its role in voluntary movement. Biophysics (1967) 12:1219-26.

120. Rossignol S, Jones GM. Audio-spinal influence in man studied by the H-reflex and its possible role on rhythmic movements synchronized to sound. Electroencephalogr Clin Neurophysiol (1976) 41:83-92. doi:10.1016/0013-4694(76)90217-0

121. Miller LC, Dewald JPA. Involuntary paretic wrist/finger flexion forces and EMGincrease with shoulder abduction load in individuals with chronic stroke. Clin Neurophysiol (2012) 123:1216-25. doi:10.1016/j.clinph.2012.01.009

122. Whitall J, Waller SM, Silver KHC, Macko RF. Repetitive bilateral arm training with rhythmic auditory cueing improves motor function in chronic hemiparetic stroke. Stroke (2000) 31:2390-5. doi:10.1161/01.STR.31.10.2390

123. Schneider S, Schönle PW, Altenmüller E, Münte TF. Using musical instruments to improve motor skill recovery following a stroke. J Neurol (2007) 254:1339. doi:10.1007/s00415-006-0523-2
124. Jun EM, Roh YH, Kim MJ. The effect of music-movement therapy on physical and psychological states of stroke patients. JClin Nurs (2013) 22:22-31. doi:10.1111/j.1365-2702.2012.04243.x

125. Pollock A, Farmer SE, Brady MC, Langhorne P, Mead GE, Mehrholz J, et al. Interventions for improving upper limb function after stroke. Cochrane Database Syst Rev (2014) 11:CD010820. doi:10.1002/14651858.CD010820. pub2

126. McMorland AJC, Runnalls KD, Byblow WD. A neuroanatomical framework for upper limb synergies after stroke. Front Hum Neurosci (2015) 9:82. doi:10.3389/fnhum.2015.00082

127. Kamper DG, Rymer WZ. Impairment of voluntary control of finger motion following stroke: role of inappropriate muscle coactivation. Muscle Nerve (2001) 24:673-81. doi:10.1002/mus.1054

128. Levin MF. Interjoint coordination during pointing movements is disrupted in spastic hemiparesis. Brain (1996) 119:281-93. doi:10.1093/brain/119. 1.281

129. Hampton S, Armstrong G, Ayyar M, Li S. Quantification of perceived exertion during isometric force production with the Borg scale in healthy individuals and patients with chronic stroke. Top Stroke Rehabil (2014) 21:33-9. doi:10.1310/tsr2101-33

130. Yen JT, Li S. Altered force perception in stroke survivors with spastic hemiplegia. J Rehabil Med (2015) 47(10):917-23. doi:10.2340/16501977-2019

131. Chang S-H, Durand-Sanchez A, DiTommaso C, Li S. Interlimb interactions during bilateral voluntary elbow flexion tasks in chronic hemiparetic stroke. Physiol Rep (2013) 1:e00010. doi:10.1002/phy2.10

132. Jahn R. Neuroscience. A neuronal receptor for botulinum toxin. Science (2006) 312:540-1. doi:10.1126/science.1127236

133. Krishnan RV. Botulinum toxin: from spasticity reliever to a neuromotor re-learning tool. Int J Neurosci (2005) 115:1451-67. doi:10.1080/00207450 590956576

134. Kaji R. Direct central action of intramuscularly injected botulinum toxin: is it harmful or beneficial? JPhysiol (2013) 591:749-749. doi:10.1113/ jphysiol.2012.246322

135. Chang SH, Francisco GE, Li S. Botulinum toxin (BT) injection improves voluntary motor control in selected patients with post-stroke spasticity. Neural Regen Res (2012) 7:1436-9.

136. Hou S, Ivanhoe C, Li S. Botulinum toxin injection for spastic scapular dyskinesia after stroke: case series. Medicine (2015) 94:e1300. doi:10.1097/ MD.0000000000001300

137. Bensmail D, Robertson J, Fermanian C, Roby-Brami A. Botulinum toxin to treat upper-limb spasticity in hemiparetic patients: grasp strategies and kinematics of reach-to-grasp movements. Neurorehabil Neural Repair (2010) 24:141-51. doi:10.1177/1545968309347683

Conflict of Interest Statement: The author declares that the research was conducted in the absence of any commercial or financial relationships that could be construed as a potential conflict of interest.

Copyright $\odot 2017$ Li. This is an open-access article distributed under the terms of the Creative Commons Attribution License (CC BY). The use, distribution or reproduction in other forums is permitted, provided the original author(s) or licensor are credited and that the original publication in this journal is cited, in accordance with accepted academic practice. No use, distribution or reproduction is permitted which does not comply with these terms. 